\title{
REAVALIAÇÃO TAXONÔMICA DE ALGUMAS ESPÉCIES DOS GÊNEROS COUSSAREA AUBL. E FARAMEA AUBL. (RUBIACEAE, TRIBO COUSSAREAE)
}

\author{
Mario Gomes ${ }^{1}$
}

\section{Recebido em 29/03/2001. Aceito em 08/03/2003}

\begin{abstract}
RESUMO - (Reavaliação taxonômica de algumas espécies dos gêneros Coussarea Aubl. e Faramea Aubl. (Rubiaceae, tribo Coussareae)). Os caracteres morfológicos de alguns táxons dos gêneros Coussarea Aubl. e Faramea Aubl., vinculados à tribo Coussareae, são reavaliados. A falta de melhor caracterização das espécies aqui incluídas tem gerado dúvidas sobre a sua verdadeira denominação, o que objetivou a elaboração deste trabalho. A análise dos caracteres resultou em melhor delimitação para os seguintes táxons: Coussarea hoehnei (K. Krause) Standl. e C. virens Müll. Arg., colocadas como sinônimos de C. contracta var. panicularis Müll. Arg.; C. cornifolia (Benth.) Müll. Arg. é relacionada a C. hydrangeifolia (Benth.) Müll. Arg. e C. porophylla (Vell.) Müll. Arg. é incluída como variedade de C. meridionalis (Vell.) Müll. Arg. Uma nova variedade de C. nodosa (Benth.) Müll. Arg. é apresentada. Para as espécies de Faramea foram feitas sinonimizações, que são: F. cyanea Müll. Arg. para F. hyacinthina Mart.; F. warmingiana Müll. Arg. e F. marginata Cham. para F. latifolia (Cham. \& Schltdl.) DC. e F. paulensis Zahlbr. para F. tetragona Müll. Arg. Inclui-se aqui também F. montevidensis (Cham. \& Schltdl.) DC., por ser comumente identificada como F. marginata Cham. Os táxons tratados neste trabalho contam com descrições mais detalhadas que as originais e chaves para as variedades, com suas principais características diagnósticas. Épocas de floração e de frutificação, distribuição geográfica, habitats, comentários gerais, material examinado como referência e a localização dos tipos completam as informações sobre os táxons.
\end{abstract}

Palavras-chave - Rubiaceae, Coussarea, Faramea, análise morfológica, taxonomia

\begin{abstract}
Taxonomic reassessment of several species of the genera Coussarea Aubl. and Faramea Aubl. (Rubiaceae, tribe Coussareae)). The morphological characteristics of several taxa of the genera Coussarea Aubl. and Faramea Aubl., linked to the tribe Coussareae, are reviewed in this paper. The species included here have been poorly described, leading to doubts concerning their proper denomination. Character analysis resulted in new limits for these species: Coussarea hoehnei (K. Krause) Standl. and C. virens Müll. Arg. are placed in synonymy with $C$. contracta var. panicularis Müll. Arg.; C. cornifolia (Benth.) Müll. Arg. is linked to C. hydrangeifolia (Benth.) Müll. Arg.; C. porophylla (Vell.) Müll. Arg. is included as a variety of C. meridionalis (Vell.) Müll. Arg. A new variety of C. nodosa (Benth.) Müll. Arg. is presented. The following species of Faramea are placed in synonymy: F. cyanea Müll. Arg. in F. hyacinthina Mart.; F. warmingiana Müll. Arg. and F. marginata Cham. in F. latifolia (Cham. \& Schltdl.) DC. and F. paulensis Zahlbr. in F. tetragona Müll. Arg. F. montevidensis (Cham. \& Schltdl.) DC. is also included here because it is commonly identified as F. marginata Cham. Descriptions of the taxa that are more detailed than the original ones are given, as well as keys to varieties with major
\end{abstract}

\footnotetext{
${ }^{1}$ mario-gomes@bol.com.br
} 
distinguishing characteristics. Data on flowering and fruiting periods, geographic distribution, habitats, general comments, representative specimen list and type localizations are also given for these taxa.

Key words - Rubiaceae, Coussarea, Faramea, morphological analysis, taxonomy

\section{Introdução}

Em continuidade aos estudos taxonômicos da família Rubiaceae, relacionados às espécies que habitam em Floresta Pluvial Atlântica (Gomes 1992; 1996; Germano Filho \& Gomes 1996; Gomes in Marques 1997; Gomes et al. 2000), em Restinga (Gomes 2001) e, mais precisamente, sobre os gêneros Coussarea Aubl. e Faramea Aubl. (Gomes 1991; 1993), ambos pertencentes à tribo Coussareae Benth. \& Hook.f., são propostos novos sinônimos para algumas de suas espécies, um status novo e uma variedade nova.

O estudo de Coussarea e Faramea para a Flora Fanerogâmica do Estado de São Paulo e o de Rubiaceae para a APA de Cairuçu, em Parati, RJ mostrou a necessidade de reexame nas identificações de algumas espécies, devido às dúvidas acerca da denominação e abrangência dos táxons.

As espécies que compõem este trabalho foram classificadas no decorrer do século XIX, ou no início do século XX. As descrições originais tiveram como base, na maior parte dos casos, uma única exsicata, fato que pode ter oferecido aos autores dados insuficientes para caracterização mais precisa. Essas descrições são, em geral, bastante reduzidas, o que vem dificultando a identificação, ou induzindo ao erro, como se tem constatado nos herbários e até mesmo em trabalhos publicados.O exame de tipos nomenclaturais veio a confirmar essa situação. Da mesma forma, foi revelada a necessidade de reavaliação dos caracteres taxonômicos das espécies que compõem este trabalho.

As pontuações translúcidas, abundantes nas folhas de Coussarea contracta, C. nodosa e Faramea hyacinthina, foram também observadas em outras espécies desses gêneros e consideradas como importantes características auxiliares na definição ou identificação de algumas espécies. Maiores informações sobre a composição e morfologia dessas minúsculas estruturas são necessárias e poderão ser obtidas com o desenvolvimento de estudos químicos e anatômicos.

Com base em análises morfológicas buscou-se delimitar mais precisamente os táxons aqui incluídos, em nível específico e infraespecífico, com o objetivo principal de fazer melhor caracterização de suas estruturas vegetativas e reprodutivas, procurando registrar as variações morfológicas observadas. A caracterização e delimitação dos táxons levou à indicação dos nomes corretos e atuais para designá-los.

\section{Material e métodos}

Os herbários institucionais consultados, ou que enviaram material para este estudo, estão listados a seguir: herbários nacionais: BAUR, BOTU, CEPEC, CVRD, ESA, GUA, HB, HISA, HRCB, IAC, IBGE, MBM, MBML, PMSP, R, RB, RBR, RFA, SP, SPF, SPSF, UB, UEC, UFG, UNBA, UPCB, VIES; herbários estrangeiros: B, BM, BR, C, F, G, K, MO, NY, $\mathrm{P}, \mathrm{S}, \mathrm{U}, \mathrm{W}, \mathrm{WU}, \mathrm{Z}$.

O material citado no texto foi examinado e, posteriormente, foram feitas comparações com as descrições originais e com os tipos nomenclaturais de espécies cujos caracteres apresentassem alguma semelhança com aquelas ainda indeterminadas. Sem exceção, foi identificado um número relativamente grande de material para cada táxon e, em virtude disto, suas características puderam ser descritas com mais abrangência. 
As exsicatas, cujas referências estão incluídas no texto, foram selecionadas seguindose os seguintes critérios: melhores condições de conservação; maior variação morfológica; estado fértil; maior distribuição de duplicatas nos herbários institucionais; distribuição geográfica, com base na literatura e material de herbário, partindo-se dos países do Norte para o Sul e no Brasil, dos estados da região Norte, para Nordeste, Centro-Oeste, Sudeste e Sul; e diferentes habitats de ocorrência.

As estampas foram confeccionadas com a finalidade de mostrar táxons que, em publicações anteriores, não foram ilustrados. Nas dos demais, foram delineados somente seus principais caracteres.

\section{Resultados e discussão}

1. Coussarea contracta (Walpert) Müll.Arg., Flora 58 (30): 467. 1875; in: Mart. Fl. Bras. 6(5): 92. 1881; Smith \& Downs, Sellowia 7: 66, t. 22k. 1956.

Plantas glabras. Arbusto a árvore, 2-12m alt.; ramos delgados, estriados, comprimidos. Estípulas decíduas, lisas, triangulares, acuminadas. Folhas com pecíolo canaliculado, 3-25mm compr.; limbo subcoriáceo, elíptico-lanceolado, oblongo-lanceolado a ligeiramente obovado, provido de minúsculas e numerosas pontuações translúcidas por toda a superfície, base aguda a cuneada, ápice acuminado, 7-14×3-6,5cm, 5-8 pares de nervuras secundárias ascendentes, portadoras ou não de domácias nas axilas com a nervura central, em fenda, glabras ou pilosas, com cripta pouco desenvolvida. Inflorescências terminais em tirsos compactos ou piramidais; pedúnculo comprimido, 1,5-4,5cm compr.; ramos laterais tetrágonos, 0-2cm compr. Flores sésseis ou subsésseis, 1-2,5cm compr.; botões florais tetrágono-fusiformes; cálice curto, obcônico, irregularmente denteado, dentes às vezes reflexos, glandulígero na face interna, minúsculas máculas alvas na face externa; corola com tubo cilíndrico-infundibuliforme, lobos longo-triangulares, com a 1/2 ou o mesmo compr. do tubo; estames inseridos no terço superior do tubo. Fruto drupóide, elipsóide, ligeira a fortemente comprimido lateralmente, $1-1,5 \mathrm{~cm}$ compr., cálice persistente.

Chave para as variedades de Coussarea contracta

1. Pecíolo com até $1 \mathrm{~cm}$ compr.; lâmina foliar elíptico-lanceolada a oblongo-lanceolada; inflorescências sem ramos laterais; frutos acentuadamente comprimidos

1a. var. contracta

1. Pecíolo com mais de $1 \mathrm{~cm}$ compr. (até $2,5 \mathrm{~cm}$ ); lâmina foliar oblongo-obovada; inflorescências com ramos laterais de $1-2 \mathrm{~cm}$ compr.; frutos ligeiramente comprimidos.

1b. var. panicularis

\section{1a. Coussarea contracta (Walpert)} Müll.Arg. var. contracta

Fig. 1a.

Faramea contracta Walpert, in: Nov. Acad. Caes. Leop.-Carol. Nat. Cur. 19(suppl. 1): 351. 1843. Tipo: Brasil, próximo ao Rio de Janeiro, Meyen (Holotypus n. v.).

Distribuição geográfica: Argentina, Paraguai e Brasil nos Estados do Ceará, Pernambuco, Goiás, Minas Gerais, Rio de Janeiro, São Paulo, Paraná e Santa Catarina.

Habitats: Floresta Pluvial Atlântica montana, Cerrado, Floresta de Galeria e Tabuleiro.

Dados fenológicos: floração mais acentuada em outubro e novembro. Frutos desenvolvidos ou maduros em maio e junho.

Material selecionado: BRASIL. Ceará: s.d., fr., Fr. Allemão s.n. (R 24788); Pernambuco: I/1930, fl., D. B. Pickel 2295 (RB); Goiás: Alto Paraíso, XII/1991, fr., B. A. S. Pereira 1933 et al. (IBGE, RB); Minas Gerais: Caldas, II/1869, fl., fr., A. F. Regnell I.274bc (R, S); Rio de Janeiro: Rio de Janeiro, IV/1865, fl., A. F. M. Glaziou $1263 a$ (R); São Paulo: 
Pedra Bela, V/1995, fl., J. Y. Tamashiro 959 et al. (HRCB, SP, UEC); Paraná: Foz do Iguaçu, XI/1963, fl., E. Pereira 7808 et al. (HBR, RB); Santa Catarina: Ouro Verde, I/1930, fr., Gurgel 15147 (RB). PARAGUAI. San Pedro: San Estanislao, II/1975, fr., T. M. Pedersen 11035 (C).

1b. Coussarea contracta (Walpert) Müll.Arg. var. panicularis Müll. Arg., in: Mart. Fl. Bras. 6(5): 92. 1881. Tipo: Brasil, próximo ao Rio de Janeiro, Sellow 115 (Holotypus B, destruído; Lectotypus K!; foto RB!).

Fig. 1b, c.

Coussarea hoehnei (K.Krause) Standl., Publ. Field Mus. Nat. Hist. bot. ser. 11(5): 196. 1936. Syn. nov.

Faramea hoehnei K.Krause, Anex. Inst. Butantan 1(3): 25, pl. 5. 1922. Tipo: Brasil, Estado de São Paulo, município de Paranapiacaba, Reserva Biológica do Alto da Serra de Paranapiacaba, 5/12/1918, F.C. Hoehne 2.592 (Holotypus SP!).

Faramea fiebrigii K. Krause, Bot. Jahrb. 40: 347. 1908. Tipo: Paraguay, Cordillera de Altos, Fiebrig 217a (Holotypus B; foto RB!).

Coussarea virens Müll.Arg., Flora 58 (30): 467 e 476. 1875; in: Mart. Fl. Bras. 6(5): 94. 1881. Tipo: Brasil, Sellow s.n. (Holotypus B; foto F!, RB!). Syn. nov.

Distribuição geográfica: Paraguai e Brasil, nos Estados do Ceará, Bahia, Mato Grosso do Sul, Minas Gerais, Rio de Janeiro, São Paulo, Paraná e Santa Catarina.

Habitats: Pantanal e Floresta Pluvial Atlântica montana, às vezes em locais alagados.

Nome popular: limãozinho-do-brejo.

Dados fenológicos: floresce de setembro a dezembro; encontrada com frutos maduros em março, maio, julho e dezembro. Seus frutos são comidos pelas aves.

Material selecionado: BRASIL. Ceará: I/1859, fl., Fr. Allemão 827 (R); Bahia: Eunápolis, IX/1966, fl., P.R. Belém 2671 et al. (UB, RB); Mato Grosso do Sul: Naviraí,
XI/1981, fl., P.P. Furtado 95 (HRB, RB); Minas Gerais: Diamantina, XI/1937, fl., Mello Barreto 9873 (BH, R); Rio de Janeiro: Teresópolis, XII/1959, fl., E. de la Sota 2368 (RB); São Paulo: Tapiraí, V/1994, fr., R. MelloSilva 918 et al. (HRCB, RB, SP, SPF); Paraná: Tapejara, I/1982, fr., P.P. Furtado 148 (HRB, RB); Santa Catarina: Papanduva, XII/1962, fl., R. Klein 4006 (HBR, RB). PARAGUAI. Paraguari: Ybycui, X/1982, fl., W. Hahn 752 (PY, MO, RB).

Confirmam-se aqui as variedades desta espécie. As características mais relevantes para ambas estão ressaltadas na chave para identificação. Os principais caracteres diferenciais apresentam-se consistentes ao longo da área de distribuição geográfica dessas variedades.

Estudando as Rubiaceae de Santa Catarina, Smith \& Downs (1956) referem-se às inflorescências de $C$. contracta como sendo paniculadas, variando de bastas a sub-bastas, sem terem feito menção às variedades descritas. O material citado naquele trabalho não pôde ser examinado. Acredita-se que pertença às duas variedades, que, como foi referido acima, têm registro de ocorrência para esse Estado.

As descrições originais de Coussarea hoehnei (K.Krause) Standl. e de C. virens Müll.Arg. enquadram-se à de $C$. contracta. Após o exame do material-tipo, sobretudo ao se ter observado a conformidade dos ramos de suas inflorescências, chegou-se à conclusão de que ambas pertencem à variedade panicularis.

2. Coussarea hydrangeifolia (Benth.) Müll.Arg., Flora 58 (30): 467. 1875; in: Mart. Fl. Bras. 6(5): 94. 1881.

Fig. 1d-g.

Faramea hydrangeifolia Benth., in: Linnaea 23: 451. 1850. Tipo: Brasil, Goiás, Gardner 3.219 (Lectotypus K!, foto RB!).

Coussarea cornifolia (Benth.) Müll. Arg., Flora 58 (30): 467. 1875; in: Mart. Fl. Bras. 6(5): 95. 1881. Syn. nov. 

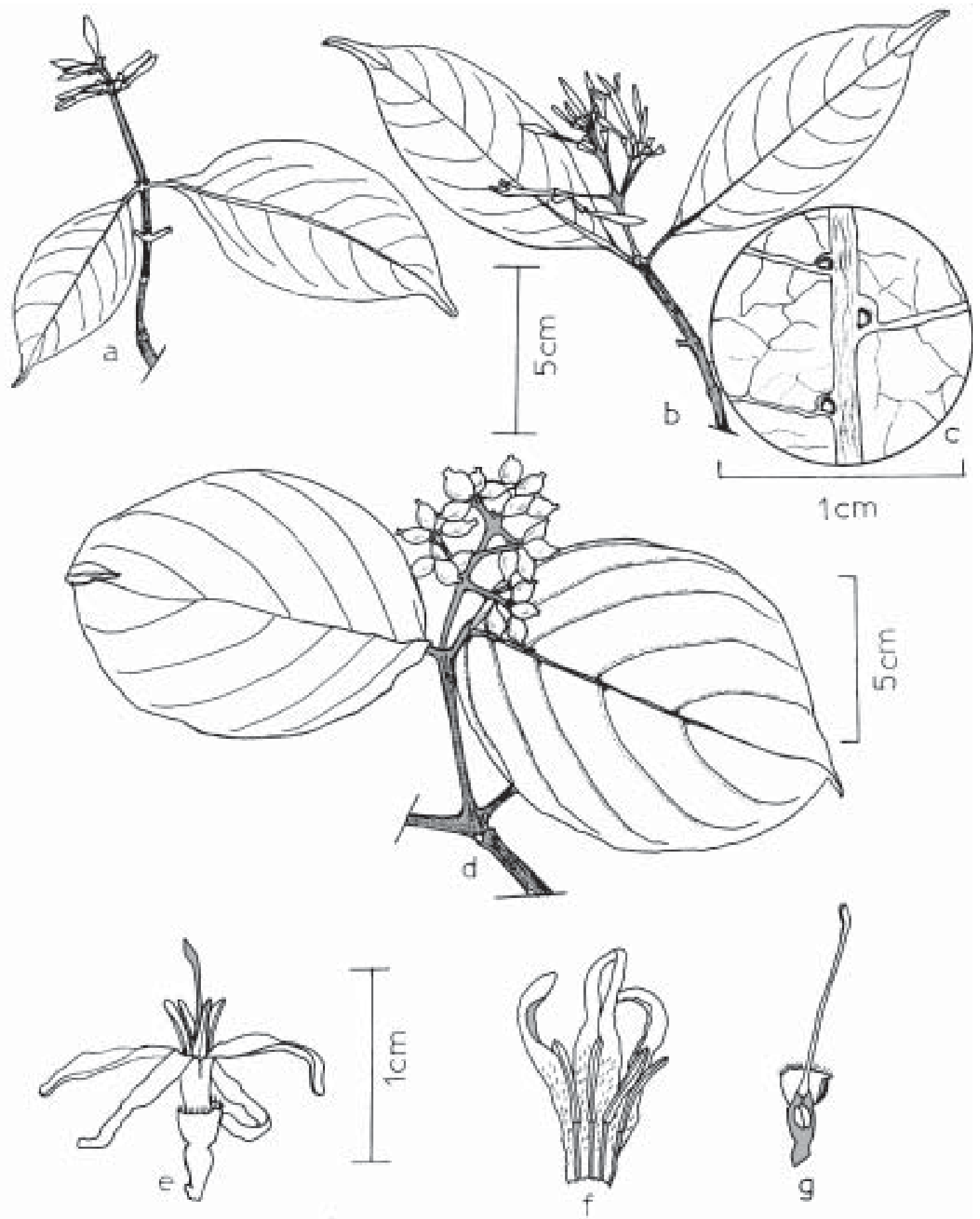

Figura 1. a. Coussarea contracta (Walpert) Müll. Arg. var. contracta: ramo florífero; b-c. Coussarea contracta var. panicularis Müll. Arg. b. ramo florífero; c. detalhe da nervura central da folha mostrando as domácias; d-g. Coussarea hydrangeifolia (Benth.) Müll. Arg. d. ramo frutífero; e. flor aberta; f. corola dissecada e estames; g. cálice e gineceu em corte longitudinal (a-Lindeman 2956; b-Sota 2368; c-Furtado 95; d-Dambrós 62; e, f, g-Lopes 14). 
Faramea cornifolia Benth., in: Linnaea 23: 450. 1850. Tipo: Brasil, Ceará, Gardner 1.695 (Lectotypus $\mathrm{K}$ !, foto $\mathrm{RB}$ !).

Arbusto a pequena árvore, 1,5-6m alt.; ramos glabros, comprimidos, pálidos, estriados. Estípulas triangulares, lisas, jovens acuminadas, desenvolvidas arredondadas. Folhas com pecíolo robusto ou delgado, canaliculado ou plano, pubescente, lado superior às vezes tomentoso, 2-5mm compr.; limbo oliváceo, nigrescente ou pardo-escuro, membranáceo a coriáceo, elíptico, oblongo ou largo-ovado, desprovido de pontuações translúcidas, base aguda a cordada, ápice agudo, arredondado ou acuminado, $8-18 \times 4,5-15 \mathrm{~cm}, 6-8$ pares de nervuras secundárias ascendentes, com intersecundárias subparalelas, domácias em tufo de pêlos. Inflorescências terminais em tirsos largo-piramidais; ramos robustos, pubescentes a tomentosos; pedúnculo 1-2,5cm compr. Flores curtamente pediceladas, ca. $1 \mathrm{~cm}$ compr.; botões tetrágonos; cálice obcônico ou urceolado, glabro, denteado, bordo ciliado, ca. $1 \mathrm{~mm}$ compr.; corola glabra na face externa, tubo cilíndrico, face interna pubérula a tomentosa, lobos lanceolados, mais longos que o tubo; estames inseridos na fauce da corola, anteras lineares, exsertas, ca. $5 \mathrm{~mm}$ compr.; ovário glabro, disco reduzido, estilete filiforme, ultrapassando a fauce, ápice bífido. Fruto drupóide elipsóide, levemente comprimido lateralmente, epicarpo com estrias longitudinais, ca. $1 \mathrm{~cm}$ compr.

Distribuição geográfica: Bolívia, Paraguai, Peru e Brasil, nos Estados do Amapá, Tocantins, Ceará, Mato Grosso, Mato Grosso do Sul, Goiás, Distrito Federal, Minas Gerais, Rio de Janeiro e São Paulo.

Habitats: Floresta Amazônica, Caatinga, Cerrado, Floresta de Galeria, Floresta Pluvial Atlântica, em alguns locais de mata perturbada.

Nomes populares e usos: chá-paraguaio, marmelada-de-cachorro, pau-terra-do-cerrado, quina-branca. Como chá-paraguaio é conhecida uma bebida preparada com as folhas desta espécie; acredita-se que possua propriedades tônicas (Standley 1931).

Dados fenológicos: produz flores por quase todo o ano, com maior freqüência em novembro e dezembro. É também encontrada com frutos maduros ou desenvolvidos de janeiro a outubro.

Material selecionado: BRASIL. Amapá: 1956, fl., Miranda Bastos 212 (RB, US); Ceará: s.d., fl., Fr. Allemão 835 (R); s.d., fl., Gardner 1.965 (K, foto RB); Mato Grosso: Cuiabá, XII/1974, fl., E.M. De Lamonica Freire 21 (RB, US); Mato Grosso do Sul: Fazenda Cainá, X/1981, fl., P.P. Furtado 67 (HRB, RB); Goiás: Meia Ponte, XI/1892, fl., E. Ule 320 (R, RB); s.d., fl., Gardner 3.222 (K, foto RB); s.d., fl., Sellow s.n. (K, foto RB); s.d., fl., Pohl s.n. (K, foto RB); s.d., fl., Clausen s.n. (K, foto RB); Distrito Federal: IX/1982, fr., J.H. Kirkbride Jr. 4894 (RB); Minas Gerais: Lagoa Santa, XI/1915, fl., F.C. Hoehne 6462 (R); Conquista, XI/1928, fl., D.L.S. Lopes 14 (RB); Rio de Janeiro: Rio Bonito, V/1976, fl., P. Laclette s.n. (R 162556); Teresópolis, V/1877, fl., A.F.M. Glaziou 10927 (R); São Paulo: Igaçaba, XI/1994 fl., W. Marcondes-Ferreira et al. 1.029 (UEC, HRCB, RB, SP); Moji-Guaçu, II/ 1977, fr., P.E.Gibbs \& H.F. Leitão-Filho 4.355 (UEC, RB, UB).

Espécie encontrada com freqüência, sendo mais abundante nas formações de Cerrado. Apresenta variações na pilosidade de várias de suas estruturas vegetativas e reprodutivas; variações nas dimensões do pecíolo, na forma, dimensões e consistência das folhas e na forma do cálice.

Müller (1875) ao relacionar Faramea cornifolia e $F$. hydrangeifolia, descritas por Bentham (1850), ao gênero Coussarea, o que não foi efetivado por Bentham \& Hooker (1873), ressaltou melhor as características diagnósticas, cujas variações estão citadas acima, evidenciando-as como espécies afins.

Ao serem examinados os tipos e as coleções históricas de ambas, localizadas nos herbários BM, BR, C, F, GH, K, NY, RB e W, além do vasto material coletado em vários Estados do 
Brasil, foi revelado que tais características variam independentemente, podendo agregar-se ora a um, ora a outro dos táxons considerados por Muller (l.c.). A corola e os frutos não apresentam variações métricas e morfológicas, sendo, portanto, considerados como bons caracteres para o táxon.

Pelo exposto, compreendeu-se que C. cornifolia e C. hydrangeifolia sejam sinônimos e neste trabalho estão sendo unidos.

3. Coussarea meridionalis (Vell.) Müll.Arg., in: Mart., Fl. Bras. 6(5): 85, t. 12. 1881.

Árvore ou arbusto, 2,5-8m alt.; partes vegetativas aéreas glabras; ramos robustos, comprimidos, sulcados, verruculosos. Estípulas subpersistentes, longo-triangulares acuminadas, face externa verruculosa, ca. $1,5 \mathrm{~cm}$ compr. Folhas com pecíolo robusto, verruculoso, 1-2,5cm compr.; limbo oliváceo, coriáceo, elíptico, largo a estreito, desprovido de pontuações translúcidas, base aguda a subaguda, ápice acuminado, $13-27 \times 5-14 \mathrm{~cm}$, nervura central robusta, verruculosa, 10-12 pares de nervuras secundárias ascendentes, proeminentes na face inferior, presença ou não de domácias em fenda nas axilas, com inter-secundárias subparalelas, reticulação evidente. Inflorescências terminais em tirsos piramidais amplos; ramos pubérulos, comprimidos; pedúnculo 4-8cm compr.; ramos laterais ascendentes; brácteas lanceoladas; pedicelos curtos. Flores ca. $2 \mathrm{~cm}$ compr; botões florais tetrágonos, ápice arredondado; cálice obcônico, pubérulo, dentes agudos, 1-2mm compr., ligeira constrição na base; corola papilosa externamente, tubo cilíndrico, lobos lanceolados, 1/2-1/3 do compr. do tubo; estames inclusos, inseridos no terço inferior ou superior do tubo, anteras lineares; disco do ovário reduzido, estilete filiforme, ápice bífido curto ou projetado além da fauce. Fruto drupóide oblongo ou obovado, epicarpo liso, máculas pálidas na superfície, base afunilada, ápice arredondado, cálice persistente, ca. $1,5 \mathrm{~cm}$ compr.
Chave para as variedades de Coussarea meridionalis

1. Folhas sem domácias......3a. var. meridionalis

1. Folhas com domácias ... 3b. var. porophylla

3a. Coussarea meridionalis (Vell.) Müll. Arg. var. meridionalis

Fig. 3a, b.

Coffea meridionalis Vell., Flor. Flum. 2 tab.14. 1831 (1827) et in Arch. Mus. Nac. Rio de Janeiro 5: 61. 1881. Tipo: Vellozo, loc. cit. t. 14 (Lectotypus).

Distribuição geográfica: Brasil: Rio de Janeiro e São Paulo.

Habitats: Floresta Pluvial Atlântica montana e baixo-montana.

Dados fenológicos: floresce em dezembro e janeiro, frutificando até outubro.

Material selecionado: BRASIL. Rio de Janeiro: Rio de Janeiro, X/1961 (fr.), A.P. Duarte 9877 (RB, US); I/1972, fl. D. Sucre 8174 (RB); XII/1987, fl., M. Gomes 264 (RB); São Paulo: Caraguatatuba, V/1966, fr., J. Mattos. s.n. (SP 101.702).

3b. Coussarea meridionalis (Vell.) Müll. Arg. var. porophylla (Vell.) M. Gomes, stat. nov.

Fig. 3c, d.

Coussarea porophylla (Vell.) Müll. Arg., in: Mart. Fl. Bras. 6(5): 86. 1881.

Coffea porophylla Vell., Fl. Flum. 2: tab. 11. 1825 (1827) et in Arch. Mus. Nac. Rio de Janeiro 5: 60. 1881. Tipo: Vellozo, loc. cit. t. 11 (Lectotypus).

Distribuição geográfica: Brasil: Rio de Janeiro e São Paulo.

Habitats: Floresta Pluvial Atlântica montana e baixo-montana.

Dados fenológicos: floresce com maior freqüência de novembro a janeiro e frutifica de fevereiro a maio.

Material selecionado: BRASIL. Rio de 
Janeiro: Magé, IV/1989, fr., M. Gomes 385 (RB); Angra dos Reis, II/1968, fl., L.B. Smith \& E.L. McWilliams 15363 (R); São Paulo: Ubatuba, Picinguaba, I/1996, fl., H.F. LeitãoFilho 34746 et al. (UEC, ESA, RB, SP); IV/1979, fr. P.P. Jouvin 459 (RB).

Esta espécie distribui-se com boa frequiência, ocorrendo em populações, em certas áreas de mata preservada do Estado do Rio de Janeiro, sendo pouco comum em São Paulo. É bem representada também nos herbários. Após a análise de farto material, verificou-se que as plantas cujas folhas são portadoras de domácias ocorrem em populações isoladas de plantas desprovidas dessa estrutura. Outras características morfológicas são comuns a ambas as populações, porém são variações de pouca relevância. Sendo a presença ou não de domácias uma característica que diferencia um grupo do outro, propõe-se aqui a inclusão de $C$. porophylla como variedade de $C$. meridionalis.

Não se pode afirmar, com as informações obtidas, se o atual isolamento entre esses táxons, considerados como infra-específicos, poderia ter ocorrido naturalmente, sem interferência humana. O que se observa é uma extensa área urbana, intermunicipal, entremeando os locais em que habitam as populações das duas variedades, no Rio de Janeiro. Para São Paulo os dados são escassos.

Barros (1959) considera que as domácias, por apresentarem alguma uniformidade em determinados grupos de plantas, podem ser, muitas vezes, constantes e específicas de variedades de uma mesma espécie - como se apresenta neste caso.

4. Coussarea nodosa (Benth.) Müll. Arg., Flora 58 (30): 467. 1875; in: Mart. Fl. Bras. 6(5): 96, t. 13.1881.

Arbusto a pequena árvore, $2-4 \mathrm{~m}$ alt.; ramos delgados, cilíndricos, jovens comprimidos, estriados, pálidos, nós engrossados. Estípulas persistentes, curtas, ovado-triangulares, lisas, 1-4mm compr. Folhas com pecíolo canaliculado, 5-15mm compr.; limbo oliváceo, membranáceo, lanceolado, oblongo-lanceolado a elíptico, provido de minúsculas e numerosas pontuações translúcidas por toda superfície, base aguda a cuneada, ápice acuminado, 2,5-18×1-4,5cm, 4-7 pares de nervuras secundárias delgadas, ascendentes, domácias em fenda, pilosas. Inflorescências em tirsos terminais sésseis, 3-radiados, ou umbelas simples; pedúnculo ou ramos laterais comprimidos, $1-2 \mathrm{~cm}$ compr.; brácteas vestigiais ou foliáceas, lineares, decíduas, 1-2cm compr.; pedicelos 1-2mm compr. Flores 1-2cm compr.; botões florais tetrágonos, ápice agudo; cálice obcônico ou cupular, truncado a curtamente denteado, membranáceo, ligeiramente pubérulo, face interna glandulígera à altura média, $1-4 \mathrm{~mm}$ compr.; corola infundibuliforme, face interna pubescente, lobos longo-triangulares, ápice arredondado, 1/2-mesma medida do tubo; estames inseridos no terço superior do tubo, anteras lineares, semi-exsertas, ca. $4 \mathrm{~mm}$ compr.; estilete incluso ou projetando-se além da fauce, ápice bífido. Fruto drupóide oblongo ou elíptico, epicarpo verruculoso, albo-amarelado, ca. $1,5 \mathrm{~cm}$ compr., cálice persistente.

Chave para as variedades de Coussarea nodosa

1. Folhas $8-18 \mathrm{~cm}$ compr., domácias pilosas com fenda circular, cripta pouco desenvolvida, arredondada; inflorescências 3-partidas; brácteas foliáceas lineares; flores ca. $1 \mathrm{~cm}$ compr.; botões florais robustos; cálice até $4 \mathrm{~mm}$ compr. 4a. var. nodosa

1. Folhas $2,5-10 \mathrm{~cm}$ compr., domácias glabras com fenda fusiforme projetada, cripta desenvolvida triangular; inflorescências em umbelas simples; brácteas vestigiais; flores $1,5-2 \mathrm{~cm}$ compr.; botões florais delgados, cálice ca. $1 \mathrm{~mm}$ compr. ..4b. var. umbellaris

4a. Coussarea nodosa (Benth.) Müll.Arg. var. nodosa

Fig. 2a-c. 
Faramea nodosa Benth., in Linnaea 23: 449. 1850. Tipo: Brasil, Rio de Janeiro, Boazini (Holotypus n. v.).

Distribuição geográfica: Brasil: Rio de Janeiro e São Paulo.

Habitats: Floresta Pluvial Atlântica montana e baixo-montana.

Dados fenológicos: floresce mais freqüentemente de setembro a novembro; frutifica até agosto.

Material selecionado: BRASIL. Rio de Janeiro: Magé, Serra da Estrella, X/1946, fl., A.C. Brade 18.647 (RB); Rio de Janeiro, Monte do Corcovado X/1989, fl., M. Gomes 410 (RB); São Paulo: Ubatuba-Picinguaba, VI/1986, fr., M. Kirizawa 1.664 (IAC, RB, SP).

\section{4b. Coussarea nodosa var. umbellaris M. Gomes, var. nov.}

Fig. 2d-i.

Hoc taxon a varietate nodosa differt, quia folia minora habet; domatia glabra cum fissura fusiformi prominenti et crypta evoluta triangulari; cymae in umbellis simplicibus, cum bracteis exiguis; flores cum calyce minore sed corolla majore, tubo et lobis gracilioribus.

Tipos: BRASIL. São Paulo: Ubatuba, Estação Experimental de Ubatuba, VIII/1939, C. Smith s.n. (Holotypus IAC 5.318, Isotypus SP); Cubatão, IX/1994, S.E. Martins 114 (Paratypus SPSF); S.E. Martins 115 (Paratypus SPSF); Ubatuba, praia de Maranduba, XI/1993, A. Spina et al. 29.815 (Paratypus UEC, Isoparatypus SP). Bahia: Una, região de mata higrófila Sul-Bahiana, IV/1980, L.A. Mattos Silva, C.C. Berg \& T.S. dos Santos 720 (Paratypus CEPLAC, Isoparatypus RB); Belmonte, solo sílico-argiloso, VII/1980, L.A. Mattos Silva \& H.S. Brito 980 (Paratypus CEPLAC, Isoparatypus RB); Espírito Santo: norte rio Doce, matas rio S. Gabriel, IX/1950, J.N. Vieira 95 (Paratypus RB, isoparatypi VIES, US); Rio de Janeiro: Petrópolis, próx. Fazenda Inglesa, ca. 1.200m.s.m., VII/1978,
H.C. de Lima 628 (Paratypus RB); Mangaratiba, Reserva Ecológica de Rio das Pedras, 330m.s.m., IX/1997, S.A.S. da Silva et al.15 (RB); Parati, morro do Carrapato, 130m.s.m., V/1994, R. Marquete 1.662 (Paratypus RB);

Distribuição geográfica: Brasil: Bahia, Minas Gerais, Espírito Santo, Rio de Janeiro e São Paulo.

Habitats: Floresta Pluvial Atlântica, Floresta Pluvial dos Tabuleiros.

Dados fenológicos: floresce de julho a setembro; frutos desenvolvidos a maduros de março a julho.

Esta espécie distribui-se em populações isoladas, às vezes com representantes que apresentam características das duas variedades. Há maior concentração de indivíduos nas matas do Rio de Janeiro, de acordo com o material depositado nos herbários.

A var. umbellaris apresenta-se com distribuição mais ampla que a var. nodosa, porém com número mais reduzido de espécimes.

O material relacionado como holótipo da var. umbellaris é o que reúne características mais distantes da var. nodosa, já mencionadas na chave. Os parátipos exibem variações, em suas formas e medidas, que a fazem se aproximar da var. nodosa, sem que perca, entretanto, identidade própria.

5. Faramea hyacinthina Mart. Flora 24 (2): 73. 1841; Müll. Arg., Flora 58(30): 473. 1875; in: Mart. Fl. Bras. 6(5): 143. 1881. Tipo: Brasil, Bahia, Blanchet 2394 (Holotypus G; Isotypi BM!, BR!, F!, K!, P, RB!, S!; foto F!, RB!).

Fig. 3e-i.

Faramea cyanea Müll. Arg., Flora 58 (30): 473 \& 479. 1875; in: Mart. Fl. Bras. 6(5): 142. 1881; Zappi \& Stannard, Fl. Pico das Almas: 559, est. 35n,p,q. 1995. Tipo: ad Lagoa Santa, E. Warming s.n. (Holotypus C!; Isotypus F!; foto F!). Syn. nov.

Arbusto 1-5m alt.; ramos delgados, jovens 


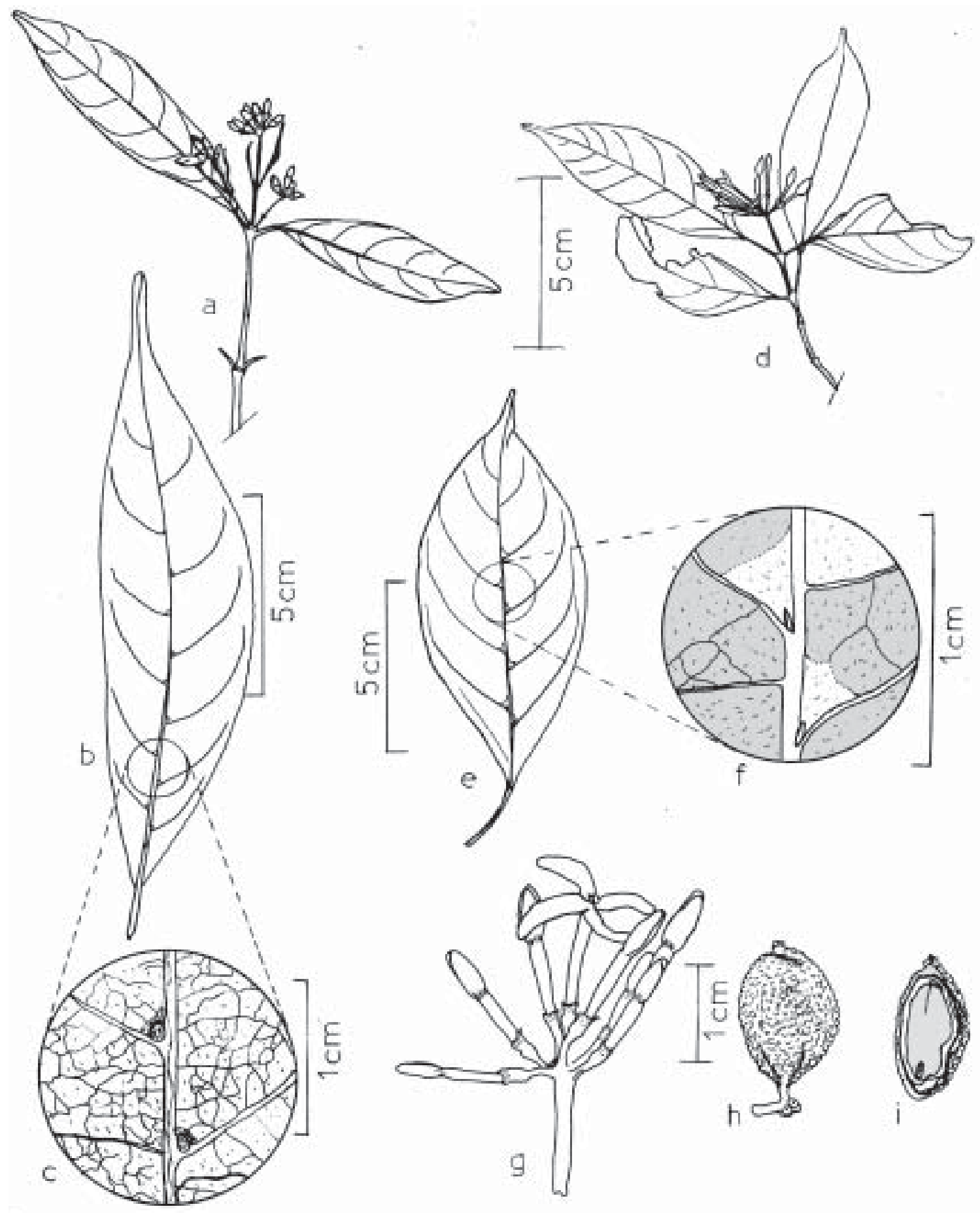

Figura 2. a-c. Coussarea nodosa (Benth.) Müll. Arg. var. nodosa. a. ramo florífero; b. folha; c. domácias; d-i. Coussarea nodosa var. umbellaris M. Gomes. d. ramo florífero; e. folha; f. domácias; g. inflorescência; h. fruto; i. fruto em corte longitudinal (a, b, c-Brade 18647; d, e, f, g-Silva 15; h, i-Mattos Silva 720). 


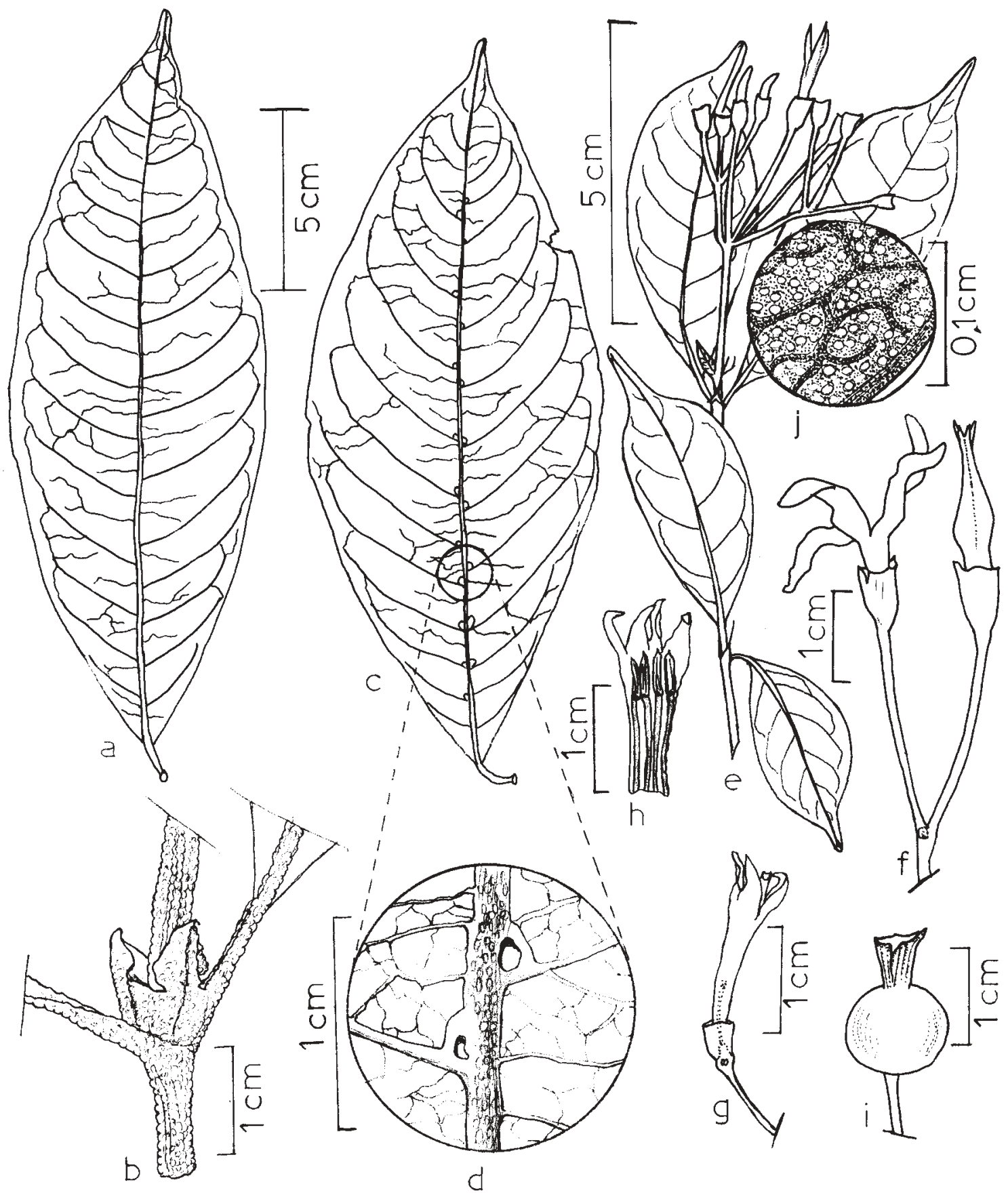

Figura 3. a-b. Coussarea meridionalis (Vell.) Müll. Arg. var. meridionalis. a. folha; b. detalhe do ramo, estípulas e pecíolos. c-d. Coussarea meridionalis var. porophylla (Vell.) M. Gomes. c. folha; d. domácias. e-j. Faramea hyacinthina Mart. e. ramo florífero; f. flor aberta e botão floral; g. flor evidenciando gineceu; h. corola dissecada e estames; i. fruto; j. pontuações translúcidas na folha (a, b-Sucre 8174; c, d-Jouvin 459; e, f, j-Lanstyack s.n.-RB 79062; g, h-Forero 8424; i-Barreto 120). 
ligeiramente comprimidos, desenvolvidos, cilíndricos, estriados. Estípulas persistentes, triangulares a arredondadas, lisas, aristas filiformes, rígidas, ca. $5 \mathrm{~mm}$ compr. Folhas com pecíolo canaliculado, 5-10mm compr.; limbo nigrescente, coriáceo, lanceolado, oblongo-lanceolado ou obovado-lanceolado, provido de minúsculas e numerosas pontuações translúcidas por toda superfície, base cuneada, ápice cuspidado, $6-14 \times 2-5,5 \mathrm{~cm}$, ca. 10 pares de nervuras secundárias delgadas, proeminentes em ambas as faces, com inter-secundárias subparalelas, menos conspícuas. Inflorescências em cimas terminais corimbosas, 5-radiadas; ramos robustos; eixo 1-2,5cm compr.; ramos laterais em tríades e em mônades; pedicelo $1-2 \mathrm{~cm}$ compr. Flores ca. $2 \mathrm{~cm}$ compr.; botões florais acuminados; cálice obcônico, truncado a curtamente denteado, às vezes unidenteado, ca. $3 \mathrm{~mm}$ compr.; corola com tubo cilíndrico-infundibuliforme, lobos longo-triangulares agudos, $1 / 2$ a quase o mesmo comprimento do tubo; estames inseridos no terço médio ou superior do tubo, anteras com ápice agudoapiculado; estilete incluso, capiláceo, ápice bífido. Fruto drupóide esférico, epicarpo áspero, ca. $1 \mathrm{~cm}$ de diâmetro, cálice persistente.

Distribuição geográfica: Paraguai, Argentina e Brasil, nos Estados da Bahia, Minas Gerais, provavelmente no Espírito Santo, Rio de Janeiro e São Paulo.

Habitats: Cerrado, Floresta Pluvial Ripária, Campos Rupestres e em Floresta Pluvial Atlântica montana e alto-montana.

Dados fenológicos: floresce com maior freqüência em setembro e outubro; frutos desenvolvidos em fevereiro.

Material selecionado: BRASIL. Minas Gerais: Barbacena, X/1883, fl., A.F.M. Glaziou 13972 (P, R, RB); Rio de Janeiro: Itatiaia, IX/1971, fl., A.G. de Andrade 9 (R); X/1918, fl., P. Campos Porto 793 (RB, G); XI/1936, fl., L. Lanstyack s.n. (RB 79.062); II/1980, fr., R.A.A. Barreto 120 (HRB, RB); São Paulo: Moji-Guaçu, IX/1980, fl., E. Forero 8424 et al.
(COL, IAC, RB, SP).

De acordo com as descrições originais, no que se refere às estruturas vegetativas, Faramea hyacinthina e $F$. cyanea são mostradas com forte semelhança. No entanto, as flores possuem variações no comprimento, nas proporções entre lobos e tubo da corola e na altura dos estames - variações essas que são características de espécies que apresentam síndrome da heterostilia dimórfica, freqüente em Rubiaceae.

Este táxon é caracterizado pelas folhas em geral obovadas, providas de pontuações translúcidas, com base agudo-cuneada e ápice abruptamente cuspidado; cimas com ramos robustos, secundários em mônades e em tríades e flores azuis com cálice truncado ou unidenteado.

F. truncata (Vell.) Müll. Arg. é próxima e apresenta a mesma conformidade dos ramos da inflorescência, sendo que menores e mais delgados; folhas desprovidas de pontuações translúcidas; flores brancas com cálice menor, truncado ou denticulado e frutos atingindo menor desenvolvimento, com cálice também mais curto.

6. Faramea latifolia (Cham. \& Schltdl.) DC. Prodr. 4: 497. 1830; Benth., in: Linnaea 23: 453. 1850; Müll. Arg., Flora 58(30): 473. 1875; in: Mart. Fl. Bras. 6(5): 145. 1881.

Fig. 4a-e.

Tetramerium latifolium Cham. \& Schltdl., in Linnaea 4: 30. 1829. Tipo: Brasil, Rio de Janeiro, Sellow 335 (Holotypus B! Isotypus S!).

Faramea marginata Cham., in Linnaea 9: 221. 1834; Müll. Arg., Flora 58(30): 473. 1875; in: Mart. Fl. Bras. 6(5): 144. 1881. Tipo: Brasilia intra tropicos, Sellow 1026 (Holotypus B, destruído; Lectotypus G!; Isotypus F!; foto F!) Syn. nov.

Faramea warmingiana Müll. Arg., Flora 58 (30): 472, 478. 1875; in: Mart. Fl. Bras. 6(5): 135. 1881. Tipos: Brasil, Minas Gerais, Lagoa Santa, E. Warming (Lectotypus C!, foto RB!) Syn. nov. 
Arbusto a árvore 2-8m alt.; ramos delgados ou robustos, pálidos, estriados, jovens comprimidos. Estípulas orbiculares, lisas, aristas subdorsais ca. $5 \mathrm{~mm}$ compr. Folhas com pecíolo canaliculado, estriado, ca. $1 \mathrm{~cm}$ compr.; limbo escuro-oliváceo, nítido, coriáceo, marginado, oblongo a oblongo-lanceolado, desprovido de pontuações translúcidas na superfície, base obtusa a aguda, ápice cuspidado a acuminado, 8-16×2,5-7,5cm, nervuras pálidas, proeminentes na face inferior, central robusta, ca. 10 pares de nervuras secundárias delgadas, unidas próximo da margem, com intersecundárias subparalelas menos conspícuas. Inflorescências em cimas terminais corimbosas, 5-radiadas, ramos comprimidos, delgados na floração, robustos na frutificação; pedúnculo 1,5-4cm compr.; ramos laterais em dicásios, raro em tríades ou em mônades; pedicelo ca. $5 \mathrm{~mm}$ compr. Flores ca. $2 \mathrm{~cm}$ compr.; botões florais tetrágonos; cálice obcônico ou cupular, truncado ou denticulado, ca. $1 \mathrm{~mm}$ compr., com máculas (glândulas?) pouco evidentes na face interna, mais escuras nos frutos; corola com tubo cilíndrico, lobos longo-triangulares, ca. 1/2 do comprimento do tubo; estames inseridos no terço superior do tubo, anteras semi-exsertas, apiculadas, ca. $4 \mathrm{~mm}$ compr. Fruto drupóide, comprimido dorsiventralmente, epicarpo liso, ca. $8 \mathrm{~mm}$ compr., cálice persistente.

Distribuição geográfica: Brasil: Goiás, Distrito Federal, Minas Gerais, Rio de Janeiro e São Paulo.

Habitats: Cerrado, Floresta Pluvial de Galeria,Campos Rupestres e Floresta Pluvial Atlântica.

Dados fenológicos: floresce de setembro a novembro. Frutos desenvolvidos ou maduros de janeiro a julho.

Material selecionado: BRASIL. Goiás: Chapada dos Veadeiros, II/1966, fr., H.S. Irwin et al. 12683 (NY, B); Minas Gerais: Barbacena, II/1883, fl., A.F.M. Glaziou 14896 (P, R); Serra do Ouro Branco, s.d., fl., A.F.M. Glaziou 14897, 14898 (C); Caldas, s.d., Regnell II. 133
(K, foto RB) sem localidade, s.d., fl., P. Claussen 666 (C); Rio de Janeiro: Rio de Janeiro, Floresta da Tijuca, s.d., fl., A.F.M. Glaziou 698 (C); São Paulo: Águas de Santa Bárbara, fl., J.Y. Tamashiro et al. 670 (SP, HRCB, RB, UEC).

Ao se comparar as descrições originais de Faramea latifolia, F. marginata e F. warmingiana, consideradas por Müller (1881) como espécies próximas, observa-se que as diferenças fundamentais entre elas são a forma e a dimensão das folhas e o comprimento dos ramos das inflorescências, o que pode ser observado, às vezes, em um único indivíduo. O exame de tipos confirmou as suspeitas de que essas três espécies poderiam ser sinônimos.

Faramea latifolia, espécie que habita preferencialmente os cerrados, tem sido encontrado com frequiência, de acordo com o vasto material depositado nos herbários. Dessa forma, pôde-se verificar que suas estruturas possuem variações que vão além daquelas assinaladas nas descrições anteriores.

7. Faramea montevidensis (Cham. \& Schltdl.) DC., Prodr. 4: 497. 1830; Benth., in: Linnaea 23: 453. 1850; Müll. Arg., Flora 58(30): 473. 1875; in: Mart. Fl. Bras. 6(5): 141. 1881; Arechavaleta, Anales del Museo Nacional de Montevideo 6(3): 34. 1906.

Fig. 4f-i.

Tetramerium montevidense Cham. \& Schltdl. Linnaea 4: 29. 1829. Tipo: In Brasilia meridionali, Sellow 298 (Holotypus B, destruído; Lectotypus G!; Isotypi F!; S!; foto F!).

Faramea marginata auct. non Cham., Smith \& Downs, Sellowia 7: 67, fig. 23 d,e. 1956.

Subarbusto, arbusto a pequena árvore 0,3-6m alt.; ramos delgados, comprimidos, estriados. Estípulas largo-triangulares ou truncadas, lisas, aristas dorsais, ca. 5mm compr. Folhas dos ramos com pecíolo canaliculado ca. $5 \mathrm{~mm}$ compr.; limbo oliváceo a nigrescente, 


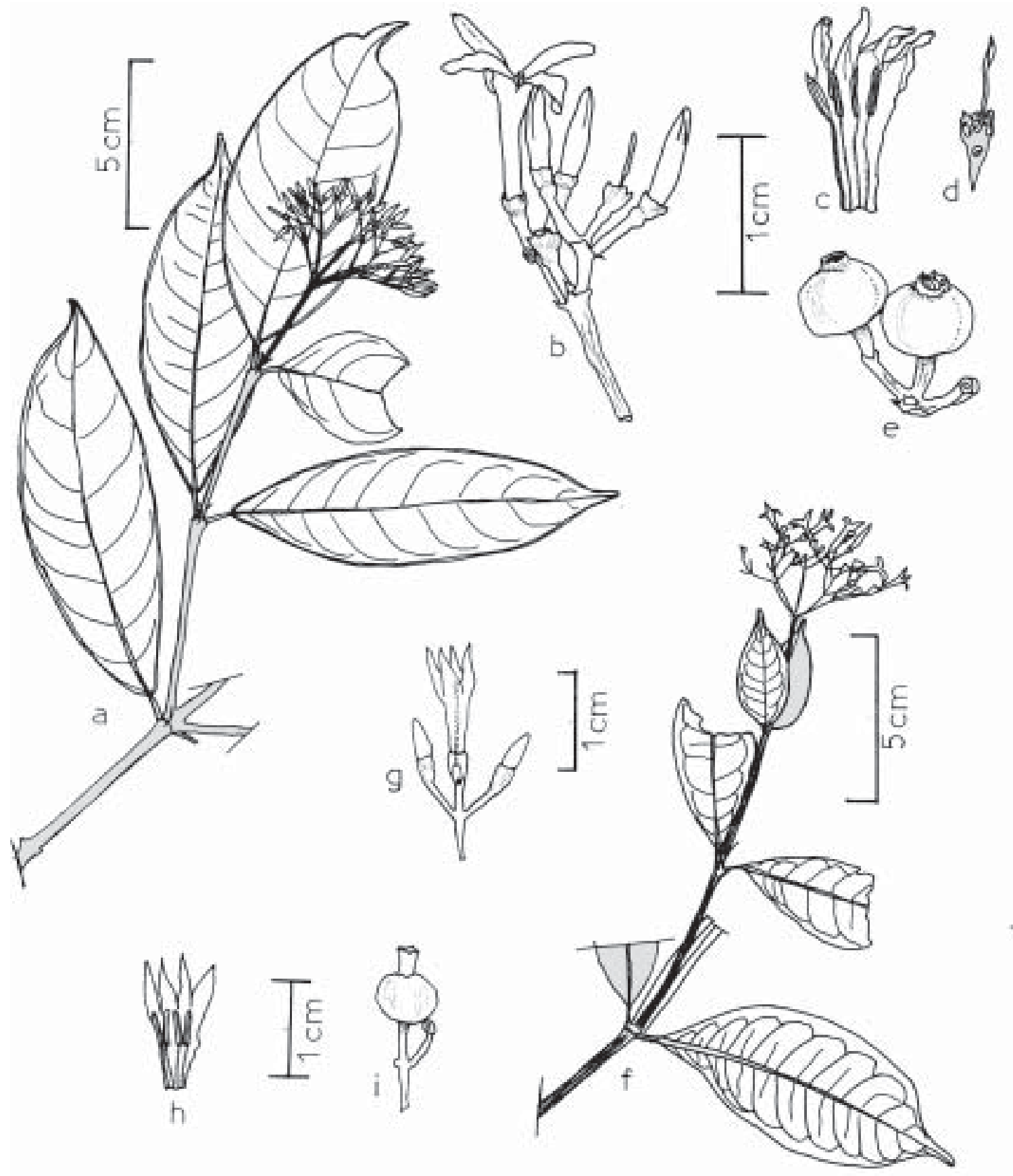

Figura 4. a-e. Faramea latifolia (Cham. \& Schltdl.) DC. a. ramo florífero; b. ramo da inflorescência, dicásio com flor aberta e botões florais; c. corola dissecada e estames; d. cálice e gineceu em corte longitudinal; e. frutos. f-i. Faramea montevidensis (Cham. \& Schltdl.) DC. f. ramo florífero; g. ramo da inflorescência, tríade com flor aberta evidenciando o gineceu e botões florais; h. corola dissecada e estames; i. fruto (a, b, c, d-Tamashiro 670; e-Duarte 8154; f, g, hHatschbach 20835; i-Veloso 107). 
coriáceo, lanceolado a elíptico-lanceolado, desprovido de pontuações translúcidas na superfície, base cuneada ou aguda, raro obtusa, ápice acuminado-cuspidado, 7-12×2-5cm, ca. 10 pares de nervuras secundárias proeminentes na face inferior, levemente ascendentes e unidas antes da margem, com inter-secundárias e reticulação evidentes; folhas na base das inflorescências menores, sésseis ou subsésseis, base truncada a cordada. Inflorescências em cimas terminais corimbosas, 5-radiadas, ramos delgados, comprimidos; pedúnculo $2,5-4 \mathrm{~cm}$ compr.; ramos laterais em dicásios ou partidos em 3 tríades; pedicelos ca. $5 \mathrm{~mm}$ compr. Flores 1-1,5cm compr.; botões florais acuminados; cálice obcônico, truncado, denticulado ou irregularmente partido, pálido, ca. $3 \mathrm{~mm}$ compr.; corola infundibuliforme, lobos longo-triangulares ca. 1/2 do comprimento do tubo; estames inseridos próximo da fauce ou no terço médio/ inferior do tubo, anteras lineares, semi-exsertas ou inclusas, apiculadas, ca. $3 \mathrm{~mm}$ compr.; disco do ovário truncado, 1/2 do comprimento do cálice, estilete incluso, bífido desde a porção mediana. Fruto drupóide globoso, comprimido dorsiventralmente, epicarpo áspero, ca. $5 \mathrm{~mm}$ compr., cálice persistente.

Distribuição geográfica: Uruguai e Brasil, nos Estados de São Paulo, Paraná, Santa Catarina e Rio Grande do Sul.

Habitats: Floresta Pluvial Atlântica montana, Restinga e bosques uruguaios.

Dados fenológicos: floresce em janeiro e fevereiro, sendo encontrada com frutos desenvolvidos de maio a setembro.

Material selecionado: BRASIL. São Paulo: Itabera, VI/1995, fr., J.Y. Tamashiro et al. 1301 (ESA, HRCB, SP, UEC); Paraná: Paranaguá, I/1969, fl., G. Hatschbach et al. 20835 (MBM, RB); Santa Catarina: Palhoça, III/1952, fl., L.B. Smith 6228 (R); Rio Grande do Sul: Pelotas, II/1978, fr., G. Martinelli 3956 (RB).

A inclusão de Faramea montevidensis neste trabalho se deve a tentar esclarecer certo equívoco que se tem feito entre esta e F. marginata, já considerada como sinônimo de F. latifolia (Cham. \& Schltdl.) DC. É o que se tem verificado nos herbários, em listas de espécies e em trabalhos publicados.

Faramea montevidensis e $F$. latifolia (marginata) são visivelmente distintas, não sendo também consideradas taxonomicamente próximas.

A espécie habita preferencialmente a região subtropical da América do Sul, ocorrendo nas proximidades da costa atlântica. Dentro dessa faixa, observa-se que a frequiência de indivíduos é mais alta nos locais de maiores latitudes. Sua ocorrência no Uruguai se dá nos bosques, à sombra das árvores, onde foi assinalada como comum (Arechavaleta 1906).

Para a flora da Argentina, F. montevidensis foi citada somente uma vez em um catálogo muito antigo, o que não se pôde confirmar. Esse registro teria sido, provavelmente, fruto de identificação equivocada, pois desde então não se detectou mais sua ocorrência (Nelida M. Bacigalupo com. pess.).

8. Faramea tetragona Müll. Arg., Flora 58 (30): 472. 1875; in: Mart. Fl. Bras. 6(5): 132. 1881. Tipo: Brasilia orientalis, Sellow s.n. (Holotypus B; foto RB!).

Fig. 5a-f.

Faramea paulensis A. Zahlbr., Anz. Akad. Wiss. Wien, Math.-Nat. 60: 83. 1924. Tipo: Prov. São Paulo, prope Raiz da Serra, 6/1901, Wettstein \& Schiffner 397 (Lectotypus WU!). Syn. nov.

Arbusto a pequena árvore 2-5m alt.; ramos delgados, tetrágonos, comprimidos. Estípulas orbiculares, verrucosas, aristas dorsais rígidas 5-15mm compr. Folhas subsésseis; limbo oliváceo, coriáceo, ovado, elíptico ou oblongo, raro lanceolado, desprovido de pontuações translúcidas na superfície, base cordada, em geral amplexicaule, ápice acuminado, 11-21×3-10cm, venação pálido-amarelada, proeminente na face inferior, nervura central robusta, ca. 10 pares de nervuras secundárias 


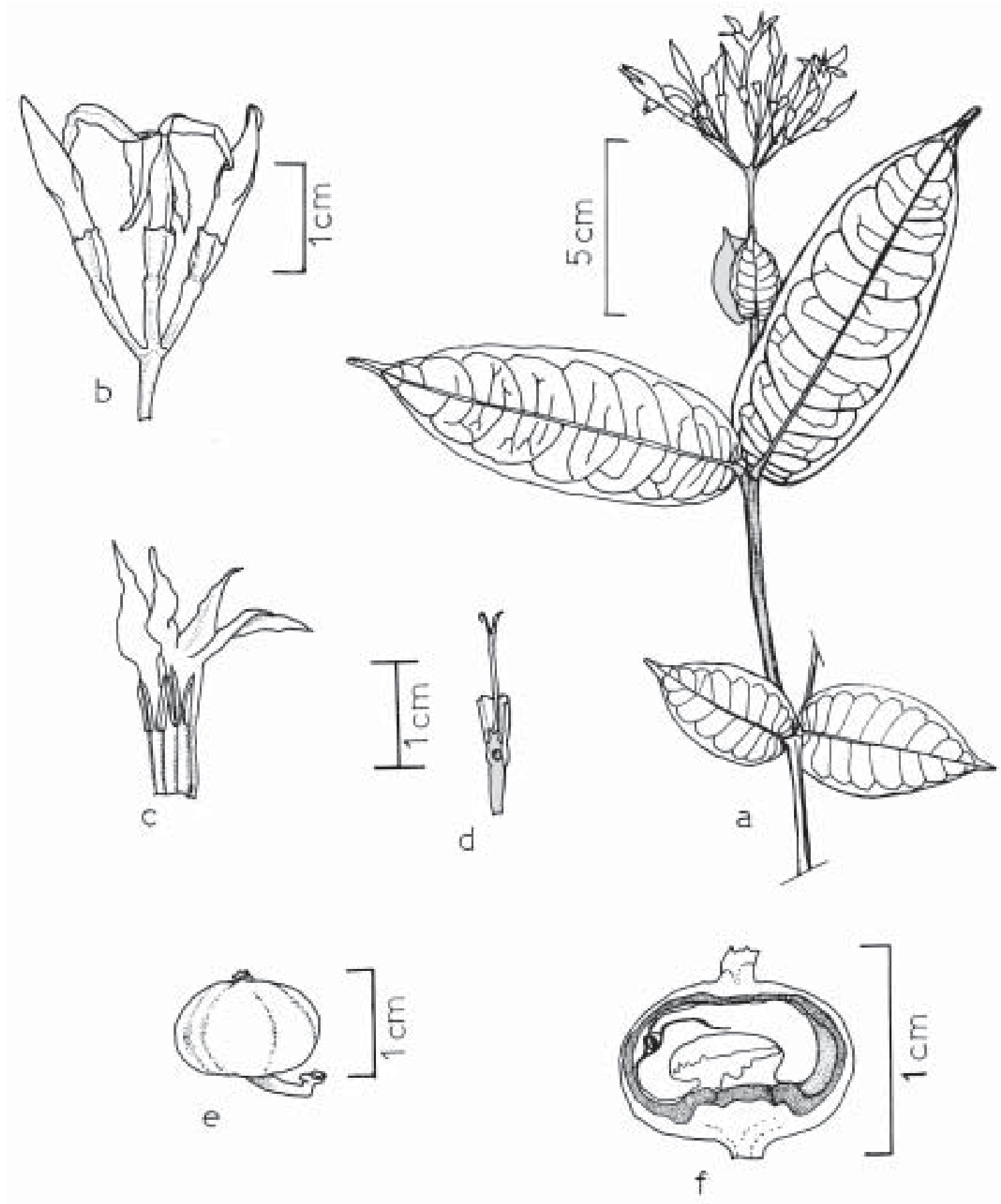

Figura 5. Faramea tetragona Müll. Arg. a. ramo florífero; b. ramo da inflorescência, tríade com flor aberta e botões florais; c. corola dissecada e estames; d. cálice e gineceu em corte longitudinal; e. fruto; f. fruto em corte longitudinal (a, b, c, d-Mariano Neto 23; e, f-Mattos 9138). 
ascendentes, unidas antes da margem. Inflorescências em cimas terminais corimbosas, 5-radiadas; ramos comprimidos, robustos; pedúnculo $2-4 \mathrm{~cm}$ compr.; ramos laterais em dicásios, tríades ou mônades. Flores 1,5-2,5cm compr.; botões florais acuminados; cálice obcônico a urceolado, truncado ou regular a irregularmente denteado, 2-5mm compr.; corola com tubo cilíndrico, lobos longo-ovados, $1 / 3$ a quase a mesma medida do tubo; estames inseridos no terço médio ou superior do tubo, anteras inclusas ou semi-exsertas, delgadas, acuminadas, ca. $5 \mathrm{~mm}$ compr.; disco do ovário reduzido, truncado, estilete incluso, ápice bífido. Fruto drupóide, comprimido dorsiventralmente, menos de $1 \mathrm{~cm}$ compr., epicarpo liso, cálice persistente.

Distribuição geográfica: Brasil: São Paulo.

Habitats: Floresta Pluvial Atlântica montana, submontana e Restinga.

Dados fenológicos: no material examinado, observou-se flores nos meses de janeiro, fevereiro, abril, maio, junho e outubro. Frutos desenvolvidos de junho a outubro.

Nome popular: casco-de-vaca.

Material selecionado: BRASIL. São Paulo: Miracatu, IX/1961, fr., J. Mattos 9.138 (IAC, RB, SP); Paranapiacaba, V/1916, fl., P. Dusén 18.099 (S); Santos, V/1875, fl., H. Mosén 3.787 (P, S); V/1875, fl., H. Mosén 3.788 (P, S); São Paulo, IV/1901, fl., Wettstein \& Schiffner 397 \& 558 (WU).

Zahlbruckner (1924) ao descrever Faramea paulensis, considerou-a espécie próxima de F. longifolia Benth., F. martiana Müll. Arg. e F. tetragona Müll. Arg.

Müller (1881) observou que $F$. longifolia e $F$. martiana assemelham-se entre si na forma das estípulas, folhas e cálice. F. tetragona foi citada como espécie bem distinta, podendo ser reconhecida por ter ramos tetrágonocomprimidos e pelas dimensões de suas flores.

Analisando o material dessas quatro espécies, verificou-se que $F$. longifolia e F. martiana são distintas entre si e das demais.
Quanto a $F$. tetragona, verificou-se que, além das características ressaltadas por Müller (l.c.), são também relevantes: folhas com base cordada e amplexicaule e limbo, em material herborizado, oliváceo com nervuras amareladas. Todas as características descritas, são observadas também em $F$. paulensis, o que não deixa dúvida de que ambas possam pertencer ao mesmo táxon.

\section{Agradecimentos}

À Dra. Dorothy Sue Dunn Araújo, do Departamento de Ecologia da UFRJ, pela revisão do Abstract; ao Prof. Dr. Miguel Barbosa do Rosário, do Departamento de Letras Clássicas da UFRJ, por seu valioso auxílio na revisão do texto em latim; à Dra. Nilda Marquete F. Silva, Curadora do Herbário do Instituto de Pesquisas Jardim Botânico do Rio de Janeiro (RB), e à sua equipe, que, com toda a cordialidade, franquearam suas dependências e serviços; ao Prof. Ronaldo Marquete e à Dra. Ângela Vaz (IBGE/ JBRJ), bem como aos coordenadores do Projeto Restinga (JBRJ), pelo uso de suas instalações.

\section{Referências bibliográficas}

Arechavaleta, J. 1906. Rubiaceae. Flora Uruguaya. Anales del Museo Nacional de Montevideo 6(3): 19-70.

Barros, M. A. A. 1959. Ocorrência das domácias na família Rubiaceae. Anais da Escola Superior de Agricultura "Luiz de Queiroz" 16: 311-337.

Bentham, G. 1850. Plantae regnellianae - Rubiaceae. Linnaea 23: 443-466.

Bentham, G. \& Hooker, J. D. 1873. Ordo LXXXIV. Rubiaceae, in: G. Bentham \& J. D. Hooker. Genera Plantarum 2: 7-151.

Germano Filho, P. \& Gomes, M. 1996. Uma nova espécie de Bathysa Presl. (Rubiaceae, Rondeletieae). Revista da Universidade Rural, Série Ciências da Vida 18(1-2): 21-23.

Gomes, D. M. S.; Arruda, R. C. O.; Gomes, M. \& Vieira, R. C. 2000. Anatomia foliar de Bathysa gymnocarpa K. Schum., B. mendonçaei K. Schum., B. cuspidata (St.Hil.) Hook. f. e B. australis (St. Hil.) Hook. f. (Rubiaceae) da Mata Atlântica, RJ, Brasil. Leandra 15: 59-72. 
Gomes, M. 1991. Uma espécie nova para a Mata Atlântica: Coussarea friburgensis (Rubiaceae, Tribo Coussareae). Eugeniana 18: 15-20.

Gomes, M. 1992. Psychotria caudata: Uma espécie nova da família Rubiaceae. Eugeniana 19: 19-23.

Gomes, M. 1993. Faramea Aubl. (Rubiaceae): Estudo taxonômico das espécies da Seção Homaloclados (Hook. f.) Müll. Arg. Dissertação de Mestrado. Universidade Federal do Rio de Janeiro/Museu Nacional, Rio de Janeiro.

Gomes, M. 1996. Rubiaceae. Pp. 345-426. In: M. P. M. Lima \& R. R. Guedes-Bruni (org.). Reserva Ecológica de Macaé de Cima, Nova Frigurgo, RJ. Aspectos Florísticos das Espécies Vasculares. Jardim Botânico do Rio de Janeiro. Ed. v. 2, Rio de Janeiro.

Gomes, M. 2001. Rubiaceae. Pp. 120-124. In: A. Costa \& I. C. A. Dias (coord.). Flora do Parque Nacional da Restinga de Jurubatiba e Arredores, Rio de Janeiro, Brasil: Listagem florística e fitogeográfica. Série Livros 8 . Museu Nacional do Rio de Janeiro, Rio de Janeiro.
Marques, M. C. M. 1997. Mapeamento da cobertura vegetal e listagem das espécies ocorrentes na Área de Proteção Ambiental de Cairuçu, Parati, RJ. Pp. 1-96. Série Estudos e Contribuições n. 13 Instituto de Pesquisas Jardim Botânico do Rio de Janeiro, Rio de Janeiro.

Müller, J. 1875. Rubiaceae brasilienses novae. Flora 58(30): 465-480.

Müller, J. 1881. Rubiaceae I. In: C. F. P. von Martius; A. W. Eichler \& I. Urban. Flora Brasiliensis..., Leipzig, München, 6(5): 1-486, t. 1-67.

Smith, L. B. \& Downs, R. J. 1956. Resumo preliminar das rubiáceas de Santa Catarina. Sellowia 7: 13-86.

Standley, P. C. 1931. The Rubiaceae of Bolivia. Publications of the Field Museum of Natural History, botanical series 7(3): 253-339.

Zahlbruckner, A. 1924 (1923). Neue arten und varietäten brasilianischer rubiaceen als ergebnisse der österreichischen südbrasilianischen expedition. Anzeiger der Akademie der Wissenschaften in Wien, Sitzung der mathematischnaturwissenschaftlichen Klasse 60: 79-87. 